\title{
A FORÇA COMO ÚNICO CONTEÚDO DA POLÍTICA. O CAPITALISMO SEGUNDO HANNAH ARENDT ${ }^{1}$
}

Jordi Carmona Hurtado (UFCG) ${ }^{2}$

zoparo@gmail.com

Resumo: Neste artigo pretendemos mostrar que existe uma crítica do capitalismo, coerente e diferenciada, na obra de Hannah Arendt, particularmente em alguns fragmentos do livro dedicado ao Imperialismo pertencente às Origens do totalitarismo, especialmente ao redor de uma leitura de Hobbes. A compreensão arendtiana do capitalismo distingue-se de outras, particularmente da marxista, no fato de mostrar que a crença segundo a qual o capitalismo seria uma lógica global e necessária é ele mesma uma ilusão social provocada pela dominação política da burguesia. O capitalismo, segundo $\mathrm{Ar}$ endt, não é uma lógica sistêmica: é uma política de força.

Palavras-chave: Arendt; capitalismo; imperialismo; Hobbes.

Pode parecer fora de lugar, arriscado ou mesmo impertinente apresentar um trabalho de pesquisa parcialmente intitulado "O capitalismo segundo Hannah Arendt". Não é talvez produto de uma confusão do autor? $\bigcirc$ título correto não seria talvez "O totalitarismo segundo Hannah Arendt"? Pois, com efeito, o nome de Hannah Arendt é geralmente associado à análise crítica do fenômeno totalitário, que tem decifrado uma série de elementos comuns no hitlerismo e

\footnotetext{
${ }^{1}$ Recebido: 07-04-2015/Aprovado: 22-07-2015/Publicado on-line: 31-08-2015.

${ }^{2}$ Jordi Carmona Hurtado é Professor adjunto I na Universidade Federal de Campina Grande, Campina Grande, PB, Brasil.
} 
no estalinismo. Ora, segundo a doxa habitual e interessada nas nossas sociedades, o liberalismo seria o contrário do totalitarismo. Portanto, pode se concluir, se Arendt foi uma grande crítica do totalitarismo, não é possível que seu ideário político seja outro que o liberal. Para completar a argumentação com alguns exemplos, é suficiente lembrar certos lugares célebres da sua obra: a superioridade aparente, no ensaio Sobre a revolução, da Revolução Americana sobre a Revolução Francesa, ou a crítica das análises da capacidade emancipatória do trabalho em Marx em A Condição Humana.

Resta que, mesmo se essa interpretação de uma Arendt liberal pode ter um aspecto convincente, é suficiente ser um leitor ocasional da obra de Arendt para se aperceber que o assunto é bem mais complexo. E ainda mais, como amiúde tem amostrado, por exemplo, Adriano Correia na academia brasileira, esse lugar-comum de uma Arendt liberal não resiste à mais leve análise dos textos. Com efeito, resulta bem complicado argumentar que Arendt é partidária de uma política centrada exclusivamente nos interesses privados quando ela não tem deixado de lembrar, por exemplo, a virtu da vida pública, da vida conduzida em um plural radical segundo as potencialidades da palavra e da ação. Arendt mostrou assim com uma grande força, que longe de o interesse político coincidir com o interesse privado, ele é comum desde a origem: o interesse público é para Arendt o contrário absoluto das arbitrariedades do indivíduo isolado. O único interesse político do homem consiste no fato de inter homines esse, e a política e os espaços públicos que ela cria são esses lugares onde uma vida em comum (e em plural) se constrói e se desenvolve, segundo lógicas diametralmente opostas à vida privada. Não há, portanto, na verdade, nada 
mais afastado do pensamento de Arendt que a identificação liberal do interesse público com o privado.

Porém, é importante, para as pessoas que consideram, como este autor, que muitos aspectos da trajetória de pensamento de Arendt podem ser extremamente úteis para as práticas e as ideias de emancipação, continuar a demonstração do a-liberalismo, senão do anti-liberalismo, das posições fundamentais de Arendt. Pois a questão é que a ficção de uma Arendt liberal não é só alimentada pelos partidários da coisa, mas também geralmente pelo marxismo, que não perdoa Arendt pelas heterodoxias supracitadas, essas que funcionam como exemplos habituais nos liberais. Por isso, a obra de Arendt fica amiúde, para assim dizer, duplamente travada: e é preciso destravá-la tanto do paraíso dos elogios liberais quanto do inferno dos anátemas marxistas. Só alguns marxistas algo mais habituados a pensar por si mesmos do que outros, como Mario Tronti ou Daniel Bensaïd $^{3}$, têm tentado assimilar para o marxismo alguns dessas posições fundamentais de Arendt, especialmente a ideia de pluralidade. E, em nossa opinião, seria uma operação saudável para o marxismo levar a sério essas considerações, e prolongar tanto a questão política da pluralidade quanto a oposição arendtiana do sistema de conselhos, como forma autêntica da política revolucionária, ao sistema de partidos. Arendt é essencial para entender a forma e o conteúdo de uma política de paz, de uma política construtiva e não só destrutiva, de uma política que se separa radicalmente da guerra. Se a gente quer que o socialismo ou o

\footnotetext{
${ }^{3}$ O leitor interessado nas recepções positivas no campo do marxismo do pensamento político de Arendt pode consultar mais particularmente: Daniel Bensaid, La politique comme art stratégique, Paris, Syllepse, 2011; Mario Tronti, La politica al tramonto, Torino, Einaudi, 1998.
} 
comunismo sejam não só a ideologia apta para a construção de uma eficiente máquina de guerra partidária contra a burguesia (cujos princípios básicos, porém, Lenine estabelece não a partir de Marx, mas de Maquiavel), mas que finalmente acaba sendo bem difícil de separar nas suas formas políticas da mesma burguesia; se a gente quer que eles sejam os princípios de construção de uma nova sociedade, radicalmente heterogênea à sociedade capitalista, pode ser que a reflexão de Arendt signifique, estranhamente, um lugar essencial para entender como isso seria possível ${ }^{4}$.

Nesse objetivo estratégico de liberar Arendt da dupla trava marxista e liberal, têm-nos parecido pertinente analisar o lugar que ocupa o capitalismo na economia discursiva da sua obra. Mas antes disso, é preciso duas advertências preliminares. A primeira é que não pretendemos argumentar - mesmo se é bem possível, e é, por exemplo, fundamental a importância na sua crítica do capitalismo da obra de Rosa Luxemburgo A acumulação do capital, que apresenta a tese da acumulação ilimitada, frente à acumulação primitiva marxiana ${ }^{5}$ - que Arendt seja uma autora marxista. Em uma discussão coletiva da sua obra, em 1972, Arendt declarou não professar, politicamente falando, nenhum credo particular (ARENDT 2010, p. 157): tampouco, portanto, o marxista. Mas esse agnosticismo ou ateísmo ideológico (que exclui, é importante dizê-lo, também o anarquismo), não impede que na mesma discussão, à pergunta sobre sua visão

\footnotetext{
${ }^{4} \mathrm{Um}$ momento importante da recente tentativa de retomar o nome de comunismo para pensar as políticas de emancipação foi a célebre conferência de Londres de 2009, na qual participaram autores como Alain Badiou, Jacques Rancière, Sussan Buck-Morss ou Slavoj Zizek. Essa conferência recebeu uma versão impressa em francês: AA. VV., L'idée du communisme, trad. Christine Vivier e Noémie Segol, Paris, Lignes, 2010.

${ }^{5}$ Cf. seu retrato de Luxemburgo em: Hannah Arendt, Homens em tempos sombrios, trad. Denise Bottman, São Paulo, Companhia das Letras, 1988.
} 
do capitalismo, ela possa responder que não era tão optimista quanto Marx ${ }^{6}$. Assim, além do que Arendt pudesse pensar sobre o conselhismo ou o socialismo, em certo modo, ela se apresenta como ainda mais anti-capitalista do que Marx: pois, segundo a lógica do seu pensamento, que não aprecia em nada a dialética, o capitalismo não poderia ser nunca um elemento positivo para o socialismo, ao começar na negação e na destruição uma obra que o socialismo vai terminar na afirmação e na construção. $O$ capitalismo, segundo Arendt, não leva em germe nenhum mundo novo de justiça. De igual modo, segundo a lógica do seu pensamento, é inadmissível a doxa estratégica marxista que considera que só é possível uma revolução socialista se primeiro houver revolução burguesa.

A tese de Arendt, como tentaremos mostrar, é a de que toda essa lógica progressista, mesmo se se trata de um progresso dialético, é uma lógica inventada pela burguesia e herdada pelo marxismo. Se o comunismo não é mais do que a culminação do capitalismo, como uma espécie de capitalismo aperfeiçoado (e só precisamos pensar, nesse respeito, na China atual), não se entende o interesse do assunto do ponto de vista da emancipação. Se, ao contrário, queremos separar a nossa compreensão das práticas de emancipação da herança liberal, pode ser interessante olhar o que possa pensar Arendt sobre o capitalismo. Mas para isso também teremos de afastar Arendt de um risco inerente às suas posições, o de que é muito fácil, ao criticar uma lógica progressista, entrar na lógica contrária, na lógica da decadência. Arendt só se salva dessa lógica de decadência que

\footnotetext{
${ }^{6}$ As palavras exatas de Arendt são, em tradução portuguesa: "Não compartilho o grande entusiasmo de Marx com relação ao capitalismo.” (ARENDT 2010, p. 158)
} 
dominaria a história e os assuntos públicos (à qual cederam, por exemplo, Heidegger ou os neoconservadores) por um milagre: o milagre da natalidade. Ou seja, pela sua confiança na capacidade dos homens quaisquer de desobedecer, de inverter os processos supostamente automáticos da história, de iniciar ações imprevisíveis que reconfiguram a relação entre os homens e o politicamente possível e impossível para eles, começando assim processos inéditos que só pertencem a eles.

Para começar é preciso se perguntar como aparece o capitalismo no discurso de Arendt. Podemos fazer a esse respeito uma constatação muito simples: Arendt raramente usa o sintagma "o capitalismo". Mas isso não significa que para ela o capitalismo não exista. É uma questão de método, o que está em jogo aqui. Pois, de certo modo, não há nada para Arendt como "o capitalismo": não há uma lógica global ou sistemática que determinaria a sociedade de baixo para cima, partindo das relações de produção. Não existe nela nenhuma teoria do reflexo no estilo marxista. E ainda mais: como temos antecipado, o fato mesmo de acreditar que tal lógica global existe, que o desenvolvimento da sociedade em todas as suas manifestações obedece a uma lógica sistemática, é precisamente um produto histórico da dominação política da burguesia. Assim, o capitalismo como lógica sistêmica, com suas próprias leis objetivas, é um fetiche burguês, podemos dizer, uma ilusão social provocada pela dominação burguesa. Nesse sentido, quanto ao método, a análise de Arendt do capitalismo nunca é uma análise científica; e isso não se explica por uma suposta incapacidade de Arendt, mas pelo fato de que o capitalismo não é nem pode ser um objeto científico para a autora. Assim, podemos observar, sobretudo em alguns capítulos do livro sobre o "Im- 
peralismo", pertencente às Origens do Totalitarismo, ao redor do apartado chamado "A emancipação política da burguesia”, no qual ela desenvolve o essencial da sua crítica do capitalismo $^{7}$, que as análises nunca são científicas. $O$ capitalismo, para Arendt, é objeto de uma tripla análise: trata-se tanto de uma análise histórica (com base na intuição essencial marxiana de que a história é a história das classes e de seus conflitos), quanto de uma análise política (ao redor dos diferentes regimes de organização das sociedades) quanto de uma filosófica (sobre os princípios e o significado desses regimes de organização).

Então, o que é o capitalismo, segundo Arendt? Em primeiro lugar, o capitalismo é um elemento plenamente localizado: ele é inteiramente coextensivo à história de uma classe determinada, à sua aparição, à sua hegemonia, e quem sabe se de sua desaparição. $O$ capitalismo é um fenômeno burguês, indissociável da existência da burguesia. Ora, em segundo lugar, ele é um elemento dividido ou distribuído: é uma coisa que circula entre o sonho liberal, a realidade do imperialismo, e o pesadelo do fascismo e do nazismo. Esses momentos são os três momentos fundamentais que determinam o fenômeno do capitalismo em Arendt. No primeiro, na utopia liberal, o capitalismo ainda não é plenamente ele mesmo: e é por isso que ele gera utopias, sonhos, fantasmas, sendo a mais célebre a "mão invisível” que mudaria o egoísmo em solidariedade, segundo

\footnotetext{
${ }^{7}$ Neste artigo, pelas limitações próprias ao gênero, vamos nos concentrar exclusivamente na análise das páginas indicadas pertencentes ao livro sobre o "Imperialismo", mas nossa interpretação supõe uma compreensão mais extensa das Origens do totalitarismo, enquanto que o imperialismo não é mais do que um dos elementos históricos ao redor dos quais, segundo Arendt, cristalizou-se o totalitarismo. Resta para outro trabalho possivel prolongar a presente pesquisa a outros lugares da obra heteróclita de Arendt, especialmente às análises que podemos chamar de mais classicamente filosóficas de A Condição Humana.
} 
Adam Smith. O segundo momento é o momento efetivo da emancipação política da burguesia, onde o capitalismo começa a governar verdadeiramente, a se apropriar do poder político, e a dar-lhe sua própria forma, a imprimir sua imagem nele, mesmo se ainda encontra algumas resistências e não destrói completamente a pluralidade. O terceiro momento é aquele em que o capitalismo finalmente não só se emancipa, passando a ser um ator hegemônico da vida política, como no caso do imperialismo, mas domina os assuntos públicos por completo: é o momento da tirania da burguesia. Ora, se no primeiro momento a burguesia (que é a portadora do capitalismo) não se conhece plenamente, autonomamente, e se no segundo ela conhece uma existência emancipada, no terceiro a burguesia arrisca-se a desaparecer $^{8}$. E isso não só aconteceu no totalitarismo estalinista, mas também no nazismo: pois temos de reconhecer que, mesmo o nazismo estando bem longe de suprimir a propriedade privada (como também não o fiz, como a gente sabe, a Rússia de Estaline, com seu capitalismo monopolista estatal), ele tentou dividir para sempre a classe dos proprietários, entre os burgueses arianos (que iam ficar com tudo, evidentemente) e os burgueses judeus, que iam ser completamente exterminados. A burguesia internacional e cosmopolita, essa burguesia liberal, ia simplesmente desaparecer

\footnotetext{
${ }^{8}$ A liquidação burguesa do Estado-nação na Alemanha durante o hitlerismo, como diz Arendt, foi, portanto, uma "vitória de Pirro" (ARENDT 1998, p. 154). Sobre a relação entre imperialismo e totalitarismo, e contra as interpretações liberais e reducionistas de Arendt, é muito esclarecedor ler o prefácio ao livro sobre o Imperialismo escrito em Junho de 1967, no momento muito específico da guerra do Vietnã: "Acentuar a infeliz relevância desse período semi-esquecido para os eventos contemporâneos não significa, naturalmente, nem que a sorte esteja lançada nem que estejamos entrando em novo período de política imperialista, nem que o imperialismo deva sempre terminar no desastre do totalitarismo." (ARENDT 1998, p. 152) Essa situação, podemos acrescentar, tem-se transmitido a grande parte dos comentadores de Arendt, que também "esquecem" habitualmente nas suas avaliações do conjunto da obra de Arendt sua crítica ao imperialismo, e principalmente a relação que ela estabelece entre a dominação burguesa e o totalitarismo.
} 
com o nazismo, para só permanecer o domínio absoluto do que Arendt chama de ralé ariana.

Ora, se o nazismo não chegou a cumprir plenamente seus propósitos, isso não significa que o mundo voltou ao velho imperialismo burguês de antes da primeira guerra mundial. Como mostra Arendt, especialmente no prefácio ao volume sobre o Imperialismo, muitos dos fenômenos totalitários permaneceram nas práticas habituais do capitalismo: assim, a inversão do tradicional privilégio da acumulação de lucro para a acumulação do poder, com as "ajudas" militares e empréstimos aos países chamados "em desenvolvimento", em lugar dos clássicos investimentos privados, para assim eles ficar perpetuamente dependentes do poder imperialista; ou as técnicas de governo de agentes secretos, de espionagem e de "governo invisível" como diz Arendt (ARENDT 1998, p. 150), a nível mundial, que são bem conhecidas, por exemplo aqui na América Latina, graças às diferentes manobras de uma grande violência, incluindo golpes de Estado, orquestradas desde as embaixadas das grandes potências capitalistas ${ }^{9}$. O capitalismo, portanto, não saiu indelével do seu devir totalitário, ao ter substituído em aparência definitivamente a política do lucro pela política do poder, e o fascismo continua sendo sua grande tentação, como podemos observar hoje facilmente na maioria dos países capitalisticamente dominantes ${ }^{10}$.

Mas a análise de Arendt centra-se no período, para as-

\footnotetext{
${ }^{9}$ Trata-se da triste sequência cujos exemplos mais célebres, mas muito longe de consistir em casos isolados, são talvez o golpe de Estado ao Chile de Allende, em 1973, e a tentativa de destabilizar a Venezuela em 2002.

${ }^{10}$ Podemos pensar, por exemplo, nos Estados Unidos após o USA Patriot Act de 2001; ou na ascensão progressiva na França do Front National, até o ponto de figurar nas últimas eleições europeias francesas como o partido mais votado, entre outros múltiplos exemplos nas nações que formam a Europa de hoje.
} 
sim dizer, clássico do capitalismo: o período imperialista. Este, como diz Arendt, e contra aquilo que pensou Lenine, talvez com um optimismo também exagerado, não é o estágio final do capitalismo, mas "o primeiro estágio do domínio político da burguesia” (ARENDT 1998, p. 168). É no imperialismo, segundo Arendt, que podemos observar da maneira mais clara os efeitos políticos do capitalismo, pois, como já temos apontado, o imperialismo constitui a figura política inventada no momento histórico da emancipação da burguesia. Pois bem, é preciso entender em primeiro lugar que, para Arendt, o imperialismo como momento clássico da hegemonia capitalista é realmente uma novidade histórica: que a política imperialista do capital não é uma simples repetição dos velhos impérios. A principal diferença, neste ponto, é a condição mesma na qual se desenvolveu o capitalismo, isto é, o Estado-nação. E se, na leitura de Arendt, Roma construiu seu Império governando a povos diversos com a mesma lei (ARENDT 1998, p. 159), as condições do Estado-nação tornaram isso impossível. Pois os Estados-nação não estão baseados em uma lei comum, que por isso poderia ser partilhada por outros povos, mas numa homogeneidade de caráter ético. Por isso, esses Estados teriam sérios limites para sua expansão (ARENDT 1998, 156 157). Porém, desde que a burguesia começa a controlar os Estados-nação, ela vai introduzir, nas suas tendências originais de expansão econômica, políticas de expansão de poder, para assegurar seus interesses no estrangeiro. $\mathrm{O}$ imperialismo como momento de emancipação da burguesia significa que a expansão econômica adquire a maturidade política, para devir assim uma política de expansão de poder. Mas os Estados-nação não podem conquistar outros povos sem considerar que são bárbaros, e lhes impor sua lei 
superior, que é produto de sua substância nacional, do modo de ser único da nação ${ }^{11}$. A conquista que começa com a violência não pode assim senão terminar na tirania. E a questão é que, segundo Arendt, essa tirania ou destruição da lei comum, própria ao imperialismo, não afeta só os domínios de ultramar; termina afetando também à metrópole (ARENDT 1998, 157). Como a gente sabe, ainda hoje muitas das técnicas militares testadas no exterior na conquista do povo bárbaro são depois aplicadas na gestão interior (ou seja, policial) da população ${ }^{12}$. Assim a burguesia não só identifica os interesses da população com seus próprios interesses, e converte o patriotismo numa questão de lucro; mas na sua divisão das nações termina praticando a guerra e tratando como inimiga a sua própria nação.

O imperialismo burguês, portanto, não é a mesma coisa que o imperialismo antigo. Ele não significa uma extensão da lei, mas uma destruição da lei comum, tanto no exterior quanto no interior. Assim, o surgimento do imperialismo burguês é inseparável do desenvolvimento do racismo moderno, como Arendt mostra longamente na segunda parte do livro sobre o Imperialismo, intitulada "O pensamento racial antes do racismo", que é mais um dos elementos importantes que Arendt detecta na origem da dominação totalitária. Por isso, se a prática imperial da burguesia não consiste numa extensão da lei, mas na sua destruição, po-

\footnotetext{
11 "Nenhum Estado-nação pode, em sã consciência, tentar conquistar povos estrangeiros, a não ser que essa consciência advenha da convicção que a nação conquistadora tem de estar impondo uma lei superior - a sua - a um povo de bárbaros." (ARENDT 1998, 156-157)

${ }^{12}$ Uns dos exemplos atuais desse fenômeno é o das técnicas policiais do tipo SWAT nos Estados Unidos aprendidas nas operações militares desenvolvidas no Oriente Próximo, e que reciclam "em casa" as armas que vão ficando obsoletas nessas guerras, que o exército vende às municipalidades a preço de saldo. Pode-se consultar, por exemplo, o artigo de Kent Paterson "Challenging a Militarized Police State in the U.S." (http://www.cipamericas.org/archives/11967, disponivel em 20 de Outubro de 2014).
} 
demos observar mais uma vez que não há leis no capitalismo; e Arendt vai mostrar, além disso, na sua análise de Hobbes, que, contra um lugar-comum muito habitual, segundo o qual a burguesia teria criado a cultura moderna e suas instituições de liberdade, incluindo a democracia, ela tem se mostrado ao invés como uma classe completamente incapaz de qualquer invenção política, como uma classe que só tem ameaçado (e essa ameaça está muito longe de ter sido superada) com destruir toda possibilidade de civilização.

Como já temos adiantado, é esse, segundo nossa leitura, o aspecto essencial da crítica arendtiana do capitalismo, e o ponto no qual Arendt se separa mais profundamente de Marx. Mesmo se, e é importante insistir, na sua análise da emancipação política da burguesia ela só tenha elogios para Marx. Arendt convoca Marx duas vezes nessas análises. A primeira é para dizer que, diante do automatismo progressista, produto da crença na acumulação ilimitada de riqueza e de poder por parte de burguesia, a utopia de progresso em Marx (o final da exploração do homem pelo homem, a sociedade sem classes) é um resto da grande ideia emancipatória do século XVIII (ARENDT 1998, 173): da ideia segundo a qual o verdadeiro progresso não se julga pelo crescimento econômico senão pela emancipação da humanidade. $\mathrm{Na}$ segunda ocasião, Arendt argumenta que só Marx entendeu que a saída imperialista à luta de classes - a divisão social sendo coberta pelo conflito exterior com outra potência -, longe de dar uma unidade estável à nação, não faz senão conduzir à guerra permanente e universal entre as nações: "O apelo à unidade assemelha-se exatamente aos gritos de alerta que sempre haviam levado os povos à guerra..." (ARENDT 1998, p. 183). 
Ora, uma vez lembrado esse reconhecimento, é importante salientar o ponto no qual Arendt se afasta mais de Marx nas suas análises. Essa distância é, como temos indicado, marcada pelo fato de Arendt achar que as supostas leis do capitalismo não são mais do que uma ilusão produzida pelo domínio burguês. Analisemos sua argumentação. Como temos falado, antes da sua emancipação imperialista (que coincide historicamente, aliás, com a derrota do movimento operário europeu, depois da experiência da comuna de Paris), o capitalismo é o conjunto de sonhos de uma classe, que é a classe dominante na produção econômica: o capitalismo é assim, durante o período liberal, o imaginário da burguesia. Esse imaginário burguês é bem simples: o passe de mágica que transformaria o interesse privado da classe da concorrência selvagem e universal ${ }^{13}$ no harmonioso interesse geral; o sonho de uma acumulação infinita de riquezas, que não conheceria nenhum limite humano, geográfico ou temporal; ou a utopia capitalista de produzir riqueza sem trabalho (e portanto, sem trabalhadores), de um processo de acumulação sem pessoas: o sonho do dinheiro gerando mais dinheiro por ele próprio (ARENDT 1998, p. 175).

Assim, não há leis do capital em Arendt, só há fenômenos da vida burguesa: apenas existe o imaginário de uma classe, e a realização complexa desse imaginário, desde que ela se emancipou. Mas qual é essa realidade, qual é a verdade do liberalismo? Essa verdade consiste no fato da burguesia transferir para a vida política seu imaginário econômico

\footnotetext{
${ }^{13}$ É muito interessante a descrição arendtiana dessa competição capitalista como essência da vida social, onde a honra e a vergonha se definem pela boa ou má sorte na concorrência (ARENDT 1998, p. 171). Para falar nos termos de Maquiavel, o capitalismo é assim o reino da pura fortuna, onde nenhuma virtu política pode se afirmar.
} 
(ARENDT 1998, p. 168). A emancipação da burguesia acontece no momento em que ela se apercebe que a acumulação infinita de riqueza com a qual ela sonha só pode se realizar mediante uma política cujo único objetivo é a acumulação ilimitada de poder. $\bigcirc$ imperialismo é a política que não exporta riqueza sem exportar ao mesmo tempo poder. Mas como já temos mostrado, essa exportação de poder é inseparável de uma destruição da lei. Assim, na sua crítica Arendt assimila amiúde o capitalismo ao crime ${ }^{14}$. Mas a questão que é preciso se colocar é a seguinte: o que é um poder separado de qualquer lei? Isso é o que Arendt vai chamar de força: assim, a grande criação política do capitalismo tem sido entender todo poder como uma força. E a crítica do capitalismo, em Arendt, não vai consistir numa crítica de Adam Smith ou de Ricardo: ela vai consistir essencialmente numa crítica a Hobbes. É aqui que passamos da análise histórico-política à análise filosófica. Pois, com efeito, Arendt vai dizer que Hobbes é o único grande filósofo que a burguesia pode contar nas suas filas ${ }^{15}$. Mais uma vez, podemos conferir a distância entre o capitalismo segundo Marx e o capitalismo segundo Arendt.

Mas é importante permanecer mais um momento no momento pré-imperialista do capitalismo. Pois a concepção política da burguesia vai ser uma herança da sua vida prépolítica. A pré-história das classes proprietárias - ou para fa-

\footnotetext{
${ }^{14}$ Ela encontra essa assimilação nas palavras mesmas de Hobbes, que mostram, segundo Arendt, que, de certo modo, o modelo do Commonwealth de Hobbes é a sociedade de criminosos, e mais concretamente, a dos assassinos; essa sociedade onde, com efeito, o interesse privado e o comum coincidem perfeitamente: "O que os mantêm juntos é um interesse comum, como, por exemplo, 'algum crime capital, pelo qual todos esperam ser punidos com a morte', tendo neste caso o direito 'de se unirem, ajudando-se e defendendo-se os uns aos outros. (...) Pois apenas defendem as suas vidas'." (ARENDT 1998, p. 170)

15 "Hobbes é, realmente, o único grande filósofo de que a burguesia pode, com direito e exclusividade, se orgulhar..." (ARENDT 1998, p. 168)
} 
lar mais propriamente, segundo a compreensão de Arendt, a pré-história das classes expropriadoras - apresenta segundo Arendt uma série de traços comuns, na sua experiência com a política. Quanto ao poder, a burguesia não teria muito interesse em exercê-lo; ela aceitaria qualquer poder sob a condição de ele proteger suas propriedades. Por isso, para a burguesia o Estado não seria outra coisa mais que uma força policial bem organizada, não tendo, em princípio, nenhum interesse político, mas só privado, sendo sua preocupação principal o lucro (ARENDT 1998, p. 168). E como temos visto, só no momento em que a continuação do lucro (da acumulação) se tornou impossível no marco do Estado-nação clássico, ela se decidiu a tomar o poder. Mas, por sua experiência pré-política com o poder, esse tomar o poder não pude se separar de uma transformação do mesmo. Hobbes, segundo Arendt, foi aquele que repensou o poder e o Estado segundo as experiências fundamentais da nova classe dominante. Por isso Hobbes vai ser o grande pensador da burguesia, e sua filosofia política vai ser a principal arma teórica da dominação política burguesa.

Essa leitura de Hobbes é, portanto, a maior originalidade da crítica arendtiana do capitalismo. Assim, por exemplo, Arendt vai mostrar que a antropologia na qual se fundamenta a teoria hobbessiana do Estado é, na verdade, uma fenomenologia da vida burguesa: o homem que é um lobo para o homem no estado de natureza, mas que não é mais que uma função no estado de sociedade, julgado como uma mercadoria pelo seu valor ou merecimento, segundo a lei da oferta e da procura; a razão que não é mais do que cálculo, a liberdade como uma palavra sem significado; e, por cima de tudo, a promoção do interesse privado ao interesse absoluto, à única justificação da existência da política. 
Assim, mais uma vez, Arendt desconstrói certa lenda heroica liberal que predomina amplamente nas representações habituais, que situa a tolerância de Locke na origem, e situa Hobbes no lugar dos autoritários: pois lembremos mais uma vez que o imperialismo ruim não é outra coisa senão a verdade e a realidade do velho e bom liberalismo.

Hobbes é então a verdade de Adam Smith: Arendt mostra assim que a instância de regulação da concorrência não é nada mais do que o poder. Mas trata-se do poder enquanto força: não há nenhuma regulação natural, nenhuma mão invisível, segundo a utopia liberal. O poder não é mais do que a força que permite que a concorrência seja vantajosa para quem detêm o poder. Vemos aqui que a definição do poder vai ser circular: mas é porque o poder é um fim em si, segundo a filosofia política burguesa; e desde que se coloca um meio na posição de fim o que se tem é uma circularidade constante, um "infinito ruim" para falar como Hegel. Desde o momento que o interesse privado vai ser elevado ao único interesse geral legítimo, a única raison d'être da sociedade não pode ser outra coisa que o desejo de poder. E isso, por quê? Segundo Arendt, a razão reside no fato de que o interesse privado é anômico: não tem nenhuma regra imanente. Por isso, o Leviatã de Hobbes é o primeiro Estado que não precisa estabelecer nenhuma regra quanto ao justo e ao injusto. A justiça se demostra no sucesso de um indivíduo ou de um grupo na sua carreira pelo poder, sendo o poder a força que permite dominar o jogo da concorrência, e portanto a acumulação da riqueza. Assim, o desejo de poder é a paixão burguesa dominante, que determina mesmo o desejo de riqueza.

Ora, quem é o cidadão deste Estado? Evidentemente, este Estado está construído sob a medida da burguesia. Mas 
há uma igualdade burguesa, uma igualdade capitalista ou liberal: a gente só precisa, como diz Arendt, considerar o dinheiro um fim em si (e não um simples meio de consumo) e, portanto, o poder como um fim em si. É a igualdade que resulta figurada no estado de natureza hobbessiano, que Arendt interpreta como a igualdade no que diz respeito ao desejo de poder. Pois qualquer um pode desejar o poder tanto como qualquer outro: e diante esse desejo, todos são iguais. E qualquer um pode matar a qualquer um para satisfazer esse desejo de poder, a fraqueza sendo compensada pela astúcia. A igualdade capitalista é, segundo as análises de Arendt, a igualdade dos criminosos, a igualdade dos assassinos.

Mas como, nessas condições, seria possível uma sociedade? A questão chave neste ponto é a segurança: pois a igualdade capitalista coloca todos os concorrentes na mesma insegurança. Assim, a raison d'être do Estado é, segundo as palavras de Arendt, "dar alguma segurança ao indivíduo, que se sente ameaçado por todos os seus semelhantes" (ARENDT 1998, p. 169). Por isso, a Commonwealth de Hobbes não está baseada na delegação do direito, mas na delegação da força: pois o único direito é a força. O Leviatã adquire assim o monopólio de matar, e dá em troca uma garantia condicional contra o risco de ser morto. A lei, nesta situação, emana diretamente da força do Estado, e não é produzida pelo homem segundo critérios do justo e do injusto. Assim, em lugar do julgamento cidadão sobre o justo e do injusto, no estado hobbessiano temos uma situação de obediência absoluta, fundamento do que Arendt chama o "cego conformismo da sociedade burguesa" (ARENDT 1998, p.170). Eis a origem das famosas "leis do capital", da famosa lógica sistêmica que regeria as sociedades capitalis- 
tas: só a obediência que é a contrapartida da seguridade, pois "como a lei flui do poder que ela torna absoluto, passa a representar a necessidade absoluta aos olhos do indivíduo que vive sob ela" (ARENDT 1998, 170). Pois a segurança que oferece o Leviatã capitalista está baseada na absoluta submissão à força que "intimida a todos": a segurança não é mais, nessas condições, do que um medo esmagador e universal, que é como o tom dominante nas sociedades capitalistas, e a outra face da ausência de política, isto é, de possibilidade de atuar. Um medo, como escreve Arendt, "que não é, exatamente, o sentimento básico do homem que se julga seguro" (ARENDT 1998, p. 172.

Esses são, em grandes traços, os aspectos fundamentais da filosofia política burguesa, que vai ter como efeito histórico primeiro o imperialismo. A "obra de civilização" que para Arendt é paradigmática dessa concepção da política foi a África do Sul: a aliança entre o capital supérfluo inglês e a ralé supérflua inglesa, na procura dessa riqueza supérflua por excelência que é o ouro. Mas toda essa superfluidade política, produto do devaneio liberal, vai produzir uma tirania de uma violência sem igual: o apartheid (ARENDT 1998, p. 180-182). É com esses meios de uma extremada violência que o capitalismo tem podido praticar suas leis; pois só quando não há nenhuma lei comum entre os brancos superiores e os negros infra-humanos, o capital pode, com efeito, produzir mais capital por si próprio: a força de trabalho dos africanos foi tratada nesse processo, com efeito, como nada, e sua participação na criação da riqueza colonial não lhes dava direito a nada, com sorte só à vida. Assim, como vai mostrar Arendt, só desde uma política cujo único conteúdo é a força, que é o contrário das representações liberais correntes, a sociedade vai poder marchar ao ritmo 
das "leis" do capitalismo. A lição de Arendt com relação ao capitalismo é assim na sua essência a seguinte: que as supostas leis naturais do capitalismo só existem por causa da obediência que concedemos àqueles que monopolizam a força nas nossas sociedades. Trata-se de mostrar que o capitalismo não tem nada de necessário, e que a filosofia política burguesa nem sequer tem podido incorporar completamente o homem à sociedade ${ }^{16}$, implica não só que uma alternativa ao capitalismo é, quanto menos, possível, mas que a política, no sentido mais geral da palavra, é na verdade o contrário do capitalismo.

Poder-se-ia argumentar, no entanto, que mesmo se nas sociedades capitalistas a vida política é bem reduzida, se não esmagada, a filosofia política burguesa tem chegado ao menos a proteger o indivíduo, e a dar ao indivíduo privado um lugar seguro na sociedade. Eis a grande certeza, a última justificativa liberal: a modesta liberdade e tranquilidade individual. Mas, diante da paisagem capitalista desenhada por Arendt, na qual o indivíduo, em lugar de concentrar o último resto de soberania, é entregue completamente à Fortuna, poderíamos nos perguntar se não estaria certo Oscar Wilde, para quem a propriedade privada é um obstáculo para o desenvolvimento das capacidades individuais (e isso não só para os proletários, mas também para os proprietários), no seu belo texto A alma do homem sob o socialismo. Mas como o objeto deste artigo era tanto mostrar que existe, com efeito, uma crítica arendtiana ao capitalismo, quanto mostrar que essa crítica não é idêntica à de Marx,

\footnotetext{
16 “(...) a participação em qualquer forma de comunidade é para Hobbes temporária e limitada, e essencialmente não muda o caráter solitário e privado do indivíduo (que não tem 'prazer mas, ao contrário, muito desgosto com manter, companhia, quando não há força para obrigá-lo a tanto'), nem cria laços permanentes entre ele e seus companheiros." (ARENDT 1998, p. 170)
} 
quereríamos terminar com uma última descrição sobre a "verdade" da liberdade liberal. Podemos observar, no seguinte trecho, como Arendt insiste no "disfarce da necessidade" que envolve, nas sociedades capitalistas, a vida comum, o que não coincide exatamente, mais uma vez, com a lenda liberal:

Despojado de direitos políticos, o indivíduo, para quem a vida pública e oficial se manifesta sob o disfarce da necessidade, adquire o novo e maior interesse por sua vida privada e seu destino pessoal. Excluído da participação na gerência dos negócios públicos que envolvem todos os cidadãos, o indivíduo perde tanto o lugar a que tem direito na sociedade quanto a conexão natural com seus semelhantes. Agora, só pode julgar sua vida privada comparando-a com a dos outros, e suas relações com os companheiros dentro da sociedade tomam a forma de concorrência. Numa sociedade de indivíduos, todos dotados pela natureza de igual capacidade de força e igualmente protegidos pelo Estado, que regula os negócios públicos e os problemas de convívio sob o disfarce da necessidade, somente o acaso pode decidir quem vencerá. (ARENDT 1998, p. 170-171)

Abstract: In this paper we argue for the existence of a critical analysis of capitalism on Hannah Arendt's work, more specifically in some fragments belonging to the book on Imperialism, from The origins of totalitarianism, and even more specifically in a certain interpretation of Hobbes. According to Arendt's understanding, with differs in some fundamental positions from the classical Marxist view, the fact of believing that capitalism is a global and necessary logic is in itself a social illusion promoted by the political hegemony of bourgeoisie. Capitalism, according to Arendt, is not a systemic logic: it's politics of force.

Keywords: Arendt; capitalism; imperialism; Hobbes.

\section{REFERÊNCIAS}

AA. VV. L'idée du communisme. Trad. Christine Vivier e Noémie Segol. Paris: Lignes, 2010.

ARENDT, Hannah. Homens em tempos sombrios. Trad. Denise Bottman, São Paulo, Companhia das Letras, 1988. 
. Origens do totalitarismo. Trad. Roberto Raposo. São Paulo: Companhia das letras, 1998.

- A condição humana. Trad. Roberto Raposo. Rio de Janeiro: Forense Universitária, 2001.

. Sobre Hannah Arendt. Trad. Adriano Correia. Inquietude. Goiânia, vol. 1, n² 2, ago/dez - 2010.

- Sobre a revolução. Trad. Denise Bottman. São Paulo: Companhia das letras, 2011.

BENSAID, Daniel. La politique comme art stratégique. Paris: Syllepse, 2011.

TRONTI, Mario. La politica al tramonto. Torino: Einaudi, 1998.

WILDE, Oscar. A alma do homem sob o socialismo. Trad. Heitor Ferreira da Costa. Porto Alegre: L\&PM, 2003. 